\title{
Relationship between Climate Change and Health of Adult Residents of Ile- Ife, Nigeria
}

\author{
Article by Ganiyu Abiodun Adedeji \\ Ph.D in Public Health, Texila American University, Guyana, South America \\ E-mail: olabode20032001@yahoo.com
}

\begin{abstract}
Background: Climate change has had a profound effect on socioeconomic, cultural, political, technological and even biological nature of man and plants in the world. This study is aimed at investigating the relationship between climate change and health of adult residents of Ile-Ife, Nigeria.

Methods: A sample survey method was used with structured questionnaire and oral interview. Random sampling technique was employed to get the sample size of 142. Informed consent of participants was obtained before commencement of the study. 142 questionnaires were duly completed and returned. Data were analyzed using frequencies, mean, standard deviation and percentages. Pearson Product Moment Correlation was employed to find the relationship between the test variables of the hypotheses.

Findings: Majority of respondents (48.6\%) had tertiary education, 20.4\% had secondary education, while $18.3 \%$ are illiterate. $42.3 \%$ got their information on climate change through radio, while only $4.9 \%$ got theirs through research institutes. $54.9 \%$ had adequate knowledge about climate change and only $9.2 \%$ had very inadequate knowledge. 37.3\% experienced malaria and headache together due to climate change, while few (0.7\%) experienced skin rashes. Significant relationship existed between the socioeconomic characteristics of the respondents and their present health status $(r=0.348, p=0.001, \alpha=0.05)$. Significant relationship was similarly found between the socioeconomic characteristics of respondents and their perception of the effect of climate change on their health $(r=0.392, p=0.001, \alpha=0.05)$.

Conclusion: Climate change had negative impacts on the health of adult residents of Ile-Ife. Governments should ensure preservation of the ozone layer and also increase awareness of the citizens on climate change and the effects on human health.
\end{abstract}

Keywords: Climate, Climate change, Health, Relationship, Adult residents, Knowledge.

\section{Introduction}

Climate change refers to some variations in the climate system that are observable to human (anthropogenic) activities, especially those that alter the atmospheric composition of the earth and ultimately lead to global warming [10]. Global warming describes the gradual increase in the average temperature of earth's atmosphere and its oceans [2].

Climate change has had a profound effect on economic, social, cultural, political, technological and even biological nature of man and plants in the global village. Generally speaking, the physical and scientific evidence which shows that the climate of the world is changing include global rise in sea levels, drought and increasing desertification, drying up of water resources as well as increase in ambient temperature [18]. According to the World Health Organization [3], climate change affects the social and environmental determinants of health such as clean air, safe drinking water, sufficient food and secure shelter globally. Similarly, the WHO has projected that between 2030 and 2050, climate change is expected to cause approximately 250,000 additional deaths per year from malnutrition, malaria, diarrhea and heat stress.

According to [19], there are many ways through which climate change affects human health. These include: increasing temperature, rising sea levels and increasing storm frequencies, all of which have 
great implications on human health as regards injury and illness. Similarly, temperature and rainfall dynamics may increase the distribution of disease vectors such as dengue fever, malaria and incidence of diarrheal diseases. Urban floods experienced by people can make them to suffer mental disorders, spread diseases, destroy houses, assets and interrupt schooling [8].

In Africa and other developing regions of the world, climate change is a treat to economic growth, long term prosperity as well as the survival of already vulnerable populations. It has thus been projected that by 2020, between 75 and 250 million people in Africa will be exposed to increased water stress due to climate change [5].

Nigeria is one of the developing countries in the sub-tropical region where the agricultural sector, landless farmers, livestock keepers, unhealthy people and those with low level of education are exposed to the risk of climate change. Nigeria has been reported to be currently experiencing increasing incidence of diseases, declining agricultural productivity, increasing number of heat waves, unreliable or erratic weather pattern, flooding, decline rainfall in already desert-prone area in the northern region causing increasing desertification and decrease food production in the north-central region [1].

Ile-Ife is an ancient city located in Osun state, in the south-western region of Nigeria. There are farmers, traders, civil servants and transporters among others residing in this ancient city who may have different perceptions of the impacts of climate variation in this area. As a result of this, the impact of climate change on the health of these people requires careful examinations in order to find solutions to the problems that may be caused by the change in climate in this area because, productivity of the inhabitants of the area, irrespective of their means of livelihood is dependent on the state of their health.

Even though, few studies have been conducted in the past that are related to this study in Nigeria, they were conducted in other regions of the country such as the north-central [1] and south-eastern regions [7]. These regions have relatively different climate and climate changes as compared to that of the area of the present study (south-western region). This study is therefore aimed at investigating the relationship between climate change and health of adult residents of Ile-Ife, Nigeria.

\section{Research questions}

(i) What are the respondents' sources of information on climate change in the study area?

(ii) What are the common ailments/diseases associated with climate change in the study area?

(iii) How knowledgeable are the respondents regarding climate change?

\section{Research hypotheses}

Ho1: There will be no significant relationship between some selected socio-economic characteristics of the adult residents of Ile-Ife and their present health status.

Ho2: There will be no significant relationship between some selected socio-economic characteristics of adult residents of Ile-Ife and their perceived effects of climate change on their health.

\section{Methodology}

The study was conducted in Ile-Ife between May and June, 2016. Ile-Ife is an ancient city located in Osun-East senatorial district of Osun State, Nigeria lying on 7.4905 degrees north and 4.5521 degrees east. The vegetation of Ile-Ife is lowland rainforest. The climate of this study area is tropical with two prominent seasons-the raining and the dry seasons. It has an area of 111 square kilometers and a population of 167,254 according to 2006 census. The residents are predominantly Yoruba tribe.

In order to achieve the aim of the study, sample survey method was used involving obtaining information with the aid of structured questionnaire coupled with oral interview of the residents of the city. Random sampling technique was used to get the sample size of 142 from the residents of the city. Informed consent of each respondent was sought and obtained before the commencement of the study. The questionnaire was administered directly to individual respondent who was willing to 
participate in the study. Wherever necessary, appropriate interpretations were made to the respondents. The questionnaire was validated by colleagues in Obafemi Awolowo University Teaching Hospitals Complex, Ile-Ife. After few modifications, it was finalized as a data collecting tool. One hundred and sixty (160) questionnaires were distributed but, due to little difficulty in accessing some of the respondents, one hundred and forty-two (142) were duly completed and returned.

The data collected were analyzed using frequencies, mean, standard deviation and percentages. Pearson Product Moment Correlation was employed to find the relationship between the test variables of the hypotheses that were generated. Data was analyzed using SPSS software version 22.0.

Ganiyu Abiodun Adedeji

The inclusion criteria were:

1. All adult males either gainfully employed or not that were residing in Ile-Ife at the time of study.

2. All adult females either gainfully employed or not that were residing in Ile-Ife at the time of study.

\section{Exclusion criteria}

The exclusion criteria were:

1. Children and teenagers either students, apprentice or neither of the two.

2. Aged men and women who could not comprehend interview.

\section{Results}

None of the respondents was below the age of 21 years as at the time of collecting data for this study. The age range that has the lowest frequency was found to be 71 years and above with only 3 respondents representing $2.1 \%$. The age range with the highest frequency is 41 to 50 years with 46 respondents and representing 32.4\%. This is followed by age range 31 to 40 years old having 41 respondents and representing $28.9 \%$. The mean age is $41.9 \pm 11.5$ years (Table 1). Out of one-hundred and forty-two respondents in this study, a larger number (91) representing $64.1 \%$ were females while, the remaining number (51) representing $35.9 \%$ were males (Table 2 ).

Table 3 shows the respondents' marital status distribution. 30 out of the142 respondents representing $21.1 \%$ were single while, majority of them (96) representing $67.6 \%$ were married. 14 among them representing 9.9\% were divorced and only 2(1.4\%) were widowed. Regarding the educational qualification of the respondents, majority of them (69) representing $48.6 \%$ had tertiary education, this is followed by those with secondary education who were 29 in number representing $20.4 \%$, twenty-six of them representing $18.3 \%$ were illiterate and $18(12.7 \%)$ had primary education (Table 4).

Table 5 shows the major sources of information on climate change for the respondents. Majority of respondents (42.3\%) got their information through radio, 28 (19.7\%) of the respondents claimed to have gotten their information on climate change through personal experience while, only 7 of the respondents representing $4.9 \%$ of total respondents got their information on climate change through research institutes. However, 15(10.6\%), 21(14.8\%) and 11(7.7\%) of the respondents got their own information on climate change through lecture, newspaper and television respectively.

A larger number of respondents (78) representing 54.9\% claimed to have adequate knowledge about climate change. Only 13(9.2\%) claimed to have very inadequate knowledge while, 35(24.6\%) have inadequate knowledge about climate change. However, 16(11.3\%) of them have very adequate knowledge of climate change (Table 6).

Table 7revealed thedistribution of respondents on the common diseases usually experienced due to climate change. 53(37.3\%) of the respondents experienced both malaria and headache together as a result of climate change showing this to be the largest number and percentage. This was followed by those that experienced malaria only who were 43 in number representing $30.3 \%$ of the respondents. Those who had typhoid fever were 11 in number representing 7.8\%. Malaria and typhoid affected 10 respondents representing $7.0 \%$, while, $6(4.2 \%)$ of the respondents were affected by cholera and 
malaria. Cold/catarrh, tuberculosis affected 5(3.5\%) and 3(2.1\%) of the respondents respectively. However, the least number of respondents $1(0.7 \%)$ experienced skin rashes due to climate change.

Regarding the test of hypothesis ' 1 ', the correlation coefficient is 0.348 . The implication of this is that there is a positive and significant relationship between the age of the respondents and their present health status $(\mathrm{p}=0.001, \mathrm{r}=0.348)$. When verified, the significant value $(\mathrm{p}=0.001)$ was lower than the critical p-value of 0.05 . In addition, there is a positive and significant relationship between the educational level of the respondents and their present health status $(p=0.001, r=0.348)$. Therefore, the null hypothesis is rejected.

On the test of hypothesis ' 2 ', the correlation coefficient is 0.392 . This implies that there is positive and significance relationship between the age of respondents and their perception of the effect of climate change on their health $(\mathrm{p}=0.001)$. This $\mathrm{p}$-value is lower than the critical $\mathrm{p}$-value of 0.05 . There is also positive and significant relationship between the educational level of the respondents and their perceived effects of climate change on their health status $(\mathrm{p}=0.001, \mathrm{r}=0.392)$. This makes the null hypothesis to be rejected.

\section{Discussion}

The socio-economic variables that were analyzed are: age, gender, marital status and level of education. This study found the mean age of respondents to be $41.9 \pm 11.5$ years. Majority of them (67.6\%) were married. This results agrees with the work of [1] where they reported the mean age of respondents in their study to be 45.5 years and that majority of the respondents (53.1\%) were married. It is also consistent with the work of [13] whose work reported that over $96 \%$ of their respondents were married. This might have something in relation to the culture of the people of Ile-Ife and that of Yoruba ethnic group in general as regards the importance attached to marriage. However, the findings of this study on gender of the respondents contradicts that of [1]. This study found more female respondents $(64.1 \%)$ as compared to more male respondents $(68.4 \%)$ that was reported by them in 2013.

On the whole, majority of the respondents were found to be literate as revealed by the result of this study. This is in line with the findings of [1] where they reported $72.4 \%$ of the respondents to be literate. This finding might be attributable to the presence of first class educational institutions both within and around Ile-Ife which is the study area. There are two universities, one polytechnic and several standard tutorial centers in Ile-Ife alone. This study again found the majority of respondents having tertiary education but, this is in contrary to the work of [12] who reported majority (32\%) of respondents in his study to have had secondary education. This might again be ascribed to the presence of educational institutions in and around Ile-Ife.

Radio was found to be the major source of information on climate change to majority of the respondents. This finding contradicts the report of [12] who reported majority of respondents' source of information on climate change to be through personal experience. However, the present finding supports the work of [1] that majority (79.2\%) of respondents in their study got information on climate change through radio. The accessibility and availability of radio as a means of communication to people of the study area might be responsible for this observation.

The highest percentage (54.9\%) of respondents in this study claimed to have adequate knowledge about climate change, while $24.6 \%$ of them did not have adequate knowledge. This finding is also consistent with the report of [12] who reported similar findings where majority of the respondents (56.67\%) claimed to have adequate knowledge and 34.0\% of them did not have adequate knowledge about climate change. The relatively high percentage of respondents that had adequate knowledge about climate change can be linked to the comparatively high percentage of literacy level of majority of the respondents in this study. This is expected to have positive impacts on how to mitigate the negative effects of climate change in the study area and its environs.

Malaria, accompanied with headache is the health condition that affected the majority of respondents in the present study as revealed by the result. The health condition that had the least 
percentage affectation as a result of climate change is skin rashes. These findings are contrary to that of [1] where malaria alone was the ailment which affected majority (31.6\%) of the respondents due to climate change. They also reported tuberculosis to be the ailment which had the least percentage affectation (2.0\%) as a result of climate change. These findings are attributable to the fact that on a general note, malaria fever is rampant in Nigeria and the fact that the study area is a tropical rain forest region of the country where mosquitoes are favorably harbored. Similarly, headache is a symptom of malaria and this might be why the two goes together in majority of respondents in this present study.

The outcome of this study revealed a positive and significant relationship between the age of the respondents and their present health status, making the null hypothesis to be rejected. This finding can be attributed to individual immunity to diseases as it relates to individual age. In many cases, it is possible that individuals of lower age group may have comparatively increased immunity. Similarly, there is a positive and significant relationship between the educational level of the respondents and their present health status. This also made the null hypothesis to be rejected. This can as well be explained by the fact that the more educated a person is, the more informed the person will be on how to care for his/her health. Education is also a socio-economic attribute of humans that increases an individual's quality of life. These findings are consistent with the work of [1] who also found positive and significant relationship between the age and education of respondents and their health status.

Furthermore, this present study found a positive and significance relationship between the age and the education level of respondents and their perception of the effect of climate change on their health. The null hypothesis is also rejected in this case. This finding also corroborate the report of [1]. They similarly reported significant relationship between respondents' age and education level and their perceived effects of climate change on their health status.

\section{Conclusion}

This study assessed the socio-economic characteristics of respondents as it relates to climate change and its effects on the health of adult residents of Ile-Ife. Radio was the commonest source of information on climate change for majority of residents of Ile-Ife and many of them had adequate knowledge about climate change. Malaria, accompanied with headache affected the highest percentage of adult residents of people of Ile-Ife. Significant relationship existed between certain socio-economic characteristics of the people of Ile-Ife and their health status as well as their perception of the effect of climate change on their health. Therefore, governments at all levels should ensure programs that will prevent cutting down of trees without replacement to preserve the ozone layer. Since information is power, the government should also find means of increasing the awareness of the citizens on climate change and the possible effects on health in particular. The means of mitigating the effects of climate change on the citizens should as well be given serious attention especially, those related to health. 


\section{Figures and tables}

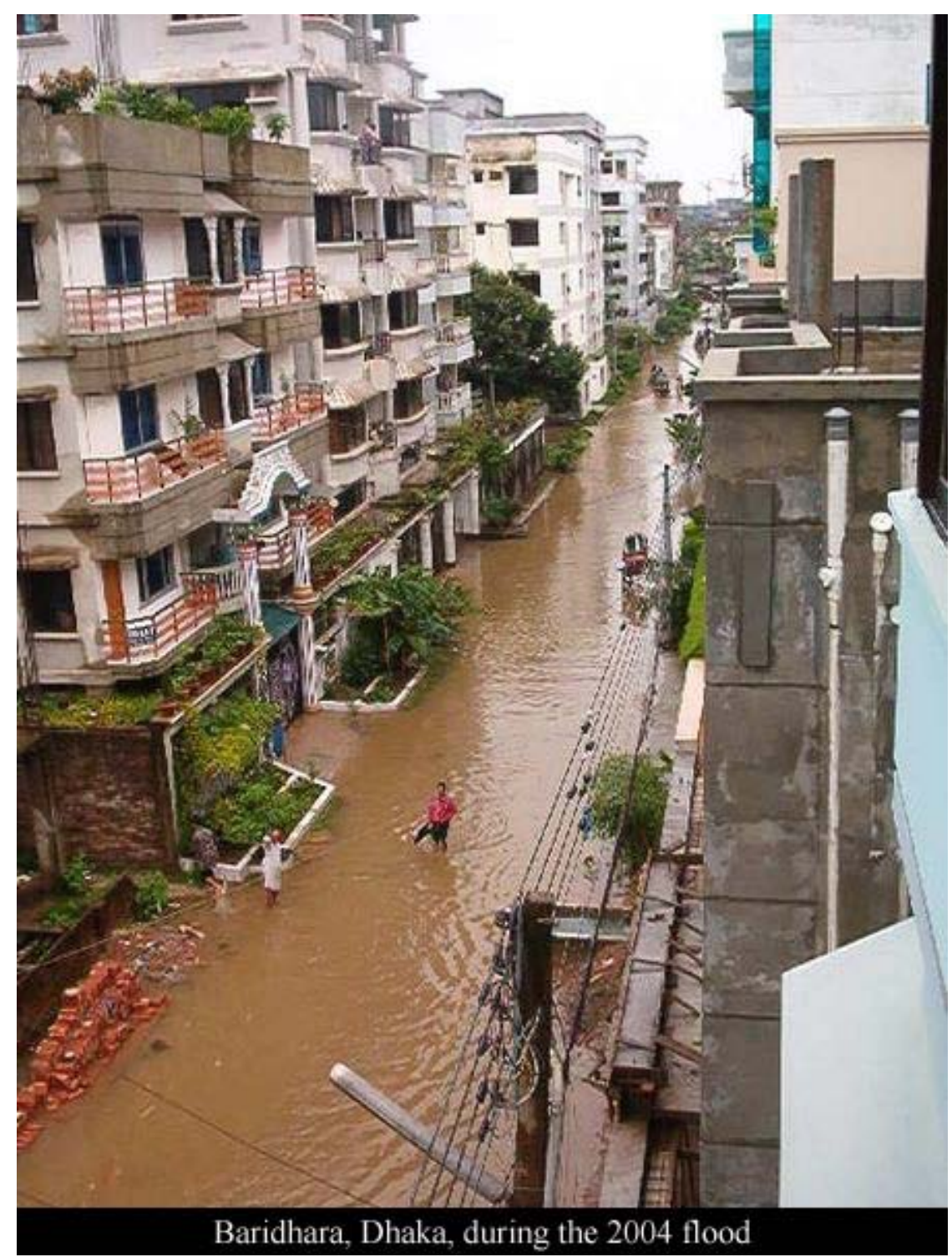

Figure 1. Flooding- A consequence of change in climate.

Table 1. Age distribution of respondents ( $n=142)$.

\begin{tabular}{lll}
\hline Characteristics & Frequency (n) & Percentage (\%) \\
\hline \multicolumn{1}{c}{ Age } & & \\
\hline $21-30$ & 21 & 14.8 \\
\hline $31-40$ & 41 & 28.9 \\
\hline $41-50$ & 46 & 32.4 \\
\hline $51-60$ & 24 & 16.9 \\
\hline $61-70$ & 7 & 4.9 \\
\hline 71 and above & 3 & 2.1 \\
\hline Mean Age=41.9 & \\
\hline
\end{tabular}


Table 2. Sex distribution of respondents $(n=142)$

\begin{tabular}{lll}
\hline Responses & Frequency (n) & Percentage (\%) \\
\hline Male & 51 & 35.9 \\
\hline Female & 91 & 64.1 \\
\hline
\end{tabular}

Table 3. Respondents marital status distribution (n=142)

\begin{tabular}{lll}
\hline Responses & Frequency (n) & Percentage (\%) \\
\hline Single & 30 & 21.1 \\
\hline Married & 96 & 67.6 \\
\hline Divorced & 14 & 9.9 \\
\hline Widowed & 2 & 1.4 \\
\hline
\end{tabular}

Table 4. Educational Qualification of respondents.

\begin{tabular}{lll}
\hline Responses & Frequency (n) & Percentage (\%) \\
\hline Illiterate & 26 & 18.3 \\
\hline Primary Education & 18 & 12.7 \\
\hline Secondary Education & 29 & 20.4 \\
\hline Tertiary Education & 69 & 48.6 \\
\hline
\end{tabular}

Table 5. Major Source of Information on Climate Change.

\begin{tabular}{lll}
\hline Source of Information & $\begin{array}{l}\text { Number of } \\
\text { Respondents (n) }\end{array}$ & $\begin{array}{c}\text { Percentage } \\
\text { (\%) }\end{array}$ \\
\hline Television & 11 & 7.7 \\
\hline Radio & 60 & 42.3 \\
\hline Lecture & 15 & 10.6 \\
\hline Newspaper & 21 & 14.8 \\
\hline Research Institute & 7 & 4.9 \\
\hline Personal Experience & 28 & 19.7 \\
\hline
\end{tabular}

Table 6: Knowledge of Respondents Regarding Climate Change.

\begin{tabular}{lll}
\hline Responses & $\begin{array}{l}\text { Number of } \\
\text { Respondents (n) }\end{array}$ & $\begin{array}{l}\text { Percentage } \\
\text { (\%) }\end{array}$ \\
\hline Very Inadequate knowledge & 13 & 9.2 \\
\hline Inadequate knowledge & 35 & 24.6 \\
\hline Very adequate knowledge & 16 & 11.3 \\
\hline Adequate knowledge & 78 & 54.9 \\
\hline
\end{tabular}

Table 7. Distribution of Respondents on the Common Diseases Usually Experienced Due to Climate Change $(n=142)$

\begin{tabular}{lll}
\hline Diseases & Frequency (n) & Percentage (\%) \\
\hline Malaria & 43 & 30.3 \\
Typhoid fever & 11 & 7.8 \\
Headache and malaria & 53 & 37.3 \\
Cholera & 3 & 2.1 \\
Headache, cholera \& & 7 & 5.0 \\
typhoid & & \\
Malaria \& typhoid & 10 & 7.0 \\
Cholera \& malaria & 6 & 4.2 \\
Tuberculosis & 3 & 2.1
\end{tabular}


Texila International Journal of Public Health

Volume 4, Issue 4, Dec 2016

\begin{tabular}{lll} 
Skin rashes & 1 & 0.7 \\
Cold \& catarrh & 5 & 3.5 \\
\hline
\end{tabular}

Hypothesis 1. The relationship between some selected socio-economic characteristics of respondents and their present health status.

\begin{tabular}{lllllll}
\hline Variable & $\mathbf{n}$ & $\mathbf{x}$ & SD & $\mathbf{R}$ & $\mathbf{P}$ & Decision \\
\hline Age & 142 & 1.19 & 0.39 & 0.348 & 0.001 & Rejected \\
Education & 142 & 1.66 & 0.52 & 0.348 & 0.001 & Rejected \\
\hline
\end{tabular}

Hypothesis 2. The relationship between some selected socio-economic characteristics of respondents and their perceived effect of climate change.

\begin{tabular}{lllllll}
\hline Variable & $\mathbf{n}$ & $\mathbf{x}$ & SD & $\mathbf{R}$ & $\mathbf{P}$ & Decision \\
\hline Age & 142 & 1.19 & 0.39 & 0.392 & 0.001 & Rejected \\
Education & 142 & 1.66 & 0.52 & 0.348 & 0.001 & Rejected \\
\hline
\end{tabular}

\section{References}

[1]. Adesiji GB, Tyabo LS, Ibrahim M, Fabiyi JO, and Oladele OA (2013). Effect of climate Change on the Health of Rural Farmers in Offa, Kwara State, Nigeria. Ethiopian Journal of Environmental studies and Management, 6(3).

[2]. Awosika LF, French GT, Nicholls RT, Ibe CE (1992). The impact of sea level rise on the coastline of Nigeria [O' Callahan J. (E.d.)] In: Global climatic change and the rising challenge of the sea. Proceedings of the IPCC workshop of Margarita Island Venezuela, 9-13. National Oceanographic and Atmospheric administration, Silver Spring, M.D., USA, pp. 690.

[3]. Canadian Institute of Actuaries (2015). Climate Change and Resource Sustainability: An Overview for Actuaries. Document 215068.

[4]. Climate change and health, Fact sheet Number 266 (2015). who.int/mediacentre/factsheets/fs266/en. Report. Summary for Policy Makers, IPCC, 2007.

[5]. Haines A, Kovats RS, Campbell-Lendrumb C, \& Corvalan, C (2006). Climate Change and Human Health: Impacts, Vulnerability and Public Health. Journal of the Royal Institute of Public Health, 120, pp. 585-596.

[6]. Idowu AA, Ayoola SO, Opele AI, Ikenweiwe NB (2011). Impact of climate change in Nigeria. Iranica Journal of Energy and Environment, 2(2): 145-152.

[7]. Odafivwotu O (2015). Public Perception of Climate Change in Yenagoa, Bayelsa State, Nigeria. Geography Journal, Article ID 208154. http://dx.doi.org/10.1155/208154.

[8]. Ojo MA and Muhammed US. (2008). Resource used efficiency in maize production among small scale farmers in Lavun Local Government Area of Niger State. International Journal of Tropical Agriculture and Food System 2(1), pp. 170-174.

[9]. Sanusi O. (2013). Climate Change: the impacts and potential benefits for the developing Nations. International Journal of Agricultural Research and Review. 1, pp. 002-012.

[10]. Tunde AM, Adeleke EA and Adeniyi EE (2013). Impact of climate variability on human health in Ilorin, Nigeria. Environment and Natural Resources Research, 3(1): pp. 488-496. 